\title{
Assistência à saúde dos homens: um desafio para os serviços de atenção primária
}

\author{
Assistance to the men health: \\ a challenge for the services of primary attention
}

\footnotetext{
${ }^{1}$ Departamento de Medicina Preventiva da Faculdade de Medicina da USP.

Av. Dr. Arnaldo 455/2o andar, sala 2242, 01246-903,

São Paulo SP.

wagfig@usp.br
}

\begin{abstract}
This article discusses how primary health care services may contribute towards men's acquisition of healthy lifestyles. This objective implies a discussion concerning health strategies focused on men as subjects and contemplating the multiple dimensions of their lives. The way in which health services are organized so as to attend users must be taken into consideration when developing these strategies. The bonds established between men and services and vice versa are also discussed. Gender and necessities of health are basic concepts utilized in the analysis of the practical experience in men's primary health care, undertaken at the Samuel B. Pessoa Health Care and Training Center, located within the Butanta neighborhood, in the city of Sao Paulo.
\end{abstract}

Key words Men's health; necessities in health; gender, primary care
Resumo O texto discute como os serviços de atenção primária podem contribuir para uma prática saudável por parte da população masculina. Tal objetivo implica a discussão de estratégias que envolvem os homens como sujeitos confrontados com as diferentes dimensões da vida; os serviços na maneira como eles se organizam para atender os usuários considerando suas particularidades; e os vinculos estabelecidos entre os homens e os serviços e vice-versa. Como fundamentação teórica, prevalecem os conceitos de gênero e de necessidade em saúde. Esses conceitos são relacionados à experiência prática desenvolvida no Centro de Saúde Escola Samuel B. Pessoa, localizado no bairro do Butantã, na cidade de São Paulo. Palavras-chave Saúde dos homens, Necessidades de saúde, Gênero, Atenção primária 
É bastante disseminada a idéia de que as unidades básicas de saúde (UBS) são serviços destinados quase que exclusivamente para mulheres, crianças e idosos. Com respeito à pouca presença masculina nos serviços de atenção primária à saúde, muitas são as suposições e/ou justificativas. Por um lado, associa-se a ausência dos homens ou sua invisibilidade, nesses serviços, a uma característica da identidade masculina relacionada a seu processo de socialização. Nesse caso, a identidade masculina estaria associada à desvalorização do auto-cuidado e à preocupação incipiente com a saúde. Por outro lado, no entanto, afirma-se que, na verdade, os homens preferem utilizar outros serviços de saúde, como farmácias ou prontos-socorros, que responderiam mais objetivamente às suas demandas. Nesses lugares, os homens seriam atendidos mais rapidamente e conseguiriam expor seus problemas com mais facilidade.

Além dessas percepções centradas no que seria próprio do comportamento dos sujeitos do sexo masculino, há também outras visões que reconhecem as UBS como sendo elas a causa da dificuldade do acesso dos homens ao serviço. Neste caso, os homens sentiriam mais dificuldades para serem atendidos, seja pelo tempo perdido na espera da assistência seja por considerarem as UBS como um espaço feminilizado, freqüentado principalmente por mulheres $\mathrm{e}$ composto por uma equipe de profissionais formada, em sua maioria, também por mulheres. Tal situação provocaria nos homens a sensação de não-pertencimento àquele espaço. Argumenta-se, ainda, que os homens não procuram as UBS porque estas não disponibilizam programas ou atividades direcionadas especificamente para a população masculina. Enfim, tudo isso indica que parece existir uma dificuldade de interação entre as necessidades de saúde da população masculina e a organização das práticas de saúde das unidades de atenção primária, embora sejam escassos estudos sobre essas questões na literatura.

Para a compreensão do que será proposto neste texto, é necessário, em princípio, admitir que a constatação da ausência dos indivíduos do sexo masculino nas UBS não deve ser pensada exclusivamente como uma falta de responsabilidade dos homens com sua saúde nem especificamente como uma falha na organização dos modelos de atenção primária à saúde. Em vez disso, a idéia é compreender o problema no contexto de uma complexa teia de relações que envolve três dimensões que interagem entre si, a saber: 1) os homens na qualidade de sujeitos confrontados com as diferentes dimensões da vida; 2 ) os serviços na maneira como eles se organizam para atender os usuários considerando suas particularidades; e 3) os vínculos estabelecidos entre os homens e os serviços e vice-versa.

Considerando esse horizonte do problema, proponho uma discussão sobre como as UBS podem contribuir para uma prática cotidiana mais saudável por parte da população masculina. Tal objetivo implica a discussão de estratégias que podem ser consideradas pelos serviços para um melhor acolhimento das necessidades em saúde dos homens. Há aqui, portanto, a noção de que, para o encaminhamento de soluções oportunas ao contexto apresentado, o papel das UBS é crucial.

Antes de avançar na discussão convém, contudo, questionar: seria mesmo necessário investir em uma proposição de assistência à saúde dos homens? Existem razões epidemiológicas para que os serviços de saúde elaborem estratégias especiais para a assistência dessa parcela da população? As respostas podem ser dadas a partir da observação dos indicadores de saúde existentes em diferentes partes do mundo. Vários estudos demonstram que, em geral, os homens vivem menos que as mulheres. Eles morrem em maior quantidade e mais cedo que a população feminina. Laurenti (1998), a partir de dados de vários países das Américas, revela que os homens tinham, em todos os países estudados, uma expectativa de vida ao nascer sempre menor quando comparada à das mulheres. Também as taxas específicas de mortalidade por faixa etária apontam para uma sobremortalidade masculina em todos os grupos etários. Portanto, os diferenciais de indicadores de mortalidade entre os sexos mostram uma situação de saúde desfavorável para os homens que precisa ser considerada e enfrentada pelos serviços de saúde.

Nesse sentido, uma primeira questão a ser debatida, para que a rede de UBS amplie seu foco de atenção também para a população masculina, diz respeito à identificação das necessidades de saúde dos homens. Como afirmam Schraiber \& Mendes-Gonçalves (2000), o reconhecimento dessas necessidades - percebidas principalmente na procura de cuidados pelos usuários - é um aspecto importante para a organização das ações de saúde. Para o universo de assistência aos homens, o reconhecimento das necessidades implica uma dificuldade a mais: como identificá-las se um dos maiores carecimentos desses indivíduos é justamente a difi- 
culdade na demanda de ações de saúde? Em outras palavras, como desenvolver, na atenção primária, estratégias tanto voltadas para as necessidades tradicionais em saúde (como recuperação e tratamentos dados) quanto voltadas para novas disposições (como prevenção e promoção da saúde masculina) sem um "contexto instaurador/receptor de necessidades"?

Uma primeira aproximação dessas necessidades pode ser alcançada observando-se, como já comentado, o perfil epidemiológico da população masculina. Retomando o estudo de Laurenti (1998), percebe-se que, quanto à taxa de mortalidade segundo causa de morte, os homens também apresentam índices mais elevados na comparação com as mulheres, na maioria das causas. $O$ trabalho também revela entre as principais causas de morte masculina as doenças cardiovasculares, as neoplasias malignas e as violências, sobressaindo os acidentes de veículo a motor e os homicídios.

Muitas dessas causas podem ser prevenidas ou controladas por meio de intervenção em atitudes e práticas cotidianas que contribuem para a ocorrência desses problemas. Entretanto, embora as informações sobre o perfil de mortalidade dos homens indiquem alguns agravos merecedores de uma atenção especial por parte dos serviços de saúde, as necessidades de saúde são também compostas por sofrimentos que não causam a morte imediata necessariamente. Ou seja, muitas das necessidades de saúde não se manifestam como um problema imediato, mas como algo evitável, na qual as UBS podem intervir com ações preventivas e de promoção à saúde.

Sendo assim, no caso dos homens existem várias atitudes e comportamentos que podem se manifestar como necessidades em saúde, as quais no âmbito das UBS podem ser abordadas mais eficientemente. Para isso, é necessário que essa abordagem se dê numa dimensão em que se considerem essas situações como algo contextualizado nas relações socioculturais em que os homens e as mulheres vivem. É partindo dessa idéia que proponho lançar mão da perspectiva de gênero para alcançar um maior conhecimento das necessidades de saúde da população masculina. Para tanto, é oportuno trabalhar com a idéia de gênero como um elemento constitutivo das relações sociais, o qual está fundamentado nas diferenças percebidas entre os sexos, sendo também uma forma primeira de significar relações de poder (Scott, 1995).

No campo da saúde, alguns estudiosos afirmam que gênero deve ser visto como um fator de grande importância na caracterização dos padrões de morbi-mortalidade masculina. Korin (2001), Sabo (2000) e Courtenay (2000) demonstram que, na construção de gênero, muitos homens assumem riscos que interferem em suas condições de saúde. Essa construção também define a forma como os homens usam e percebem os seus corpos. Nas perspectivas de seus modelos de masculinidade, os homens muitas vezes assumem comportamentos considerados pouco saudáveis, comportamentos esses que estão relacionados a um modelo de masculinidade idealizada, a masculinidade hegemônica (Connell, 1995).

Nesses modelos de masculinidade idealizada estão presentes as noções de invulnerabilidade e de comportamento de risco - como valores da cultura masculina - e a idéia de uma sexualidade instintiva e, portanto, incontrolável. Associadas a isso encontram-se fortalecidas suas dificuldades de verbalizar as próprias necessidades de saúde, pois falar de seus problemas de saúde pode significar uma possível demonstração de fraqueza, de feminilização perante os outros. Denota-se daí a idéia de feminilização associada aos cuidados de saúde.

É com essas concepções e tendo como referência os diagnósticos de saúde dos homens em cada contexto em que as UBS estão inseridas, que os serviços devem construir as estratégias assistenciais para contemplar as diferentes necessidades de saúde dos homens.

Também na perspectiva de gênero deve ser pensado o espaço das UBS. A idéia dos serviços de saúde como um espaço feminilizado precisa ser transformada de modo a incluir as necessidades de saúde dos homens. Isto não significa necessariamente apenas a mudança nos percentuais de trabalhadores homens e mulheres nesses serviços, nem muito menos a criação de serviços de saúde específicos para a população masculina. É claro que um maior número de profissionais de saúde do sexo masculino nestes serviços, principalmente na equipe de enfermagem, contribuiria para uma maior percepção de pertencimento dos homens nos postos de saúde. Porém, mais importante do que ter homens na assistência, é uma mudança da postura prática de todos os profissionais, sejam homens ou mulheres. É necessário que os profissionais de saúde tenham uma maior sensibilidade para as interações entre as concepções de gênero e as demandas trazidas pelos homens no uso do serviço.

Neste sentido, apresento para o debate propostas e ações voltadas para a população mas- 
culina, nas quais se utiliza o referencial de gênero. Refiro-me às formulações desenvolvidas no âmbito da promoção e prevenção à saúde no Centro de Saúde-Escola Prof. Samuel B. Pessoa (CSE). O CSE é uma unidade docente-assistencial, vinculada à Faculdade de Medicina da Universidade de São Paulo, que atua na cidade de São Paulo, desenvolvendo tecnologias de intervenção em atenção primária em saúde. Suas ações envolvem, entre outras, a atenção à saúde da criança, do adulto, em saúde mental e vigilância epidemiológica. Os cuidados são realizados por uma equipe multiprofissional, integrando-se modalidades educativas e assistenciais.

Desde 2002 este serviço tem se preocupado com a inexistência nos serviços de saúde de programas ou atividades que dêem conta das inúmeras necessidades de saúde dos homens. Inicialmente, a preocupação estava centrada na dificuldade encontrada por diversos profissionais do CSE em responder adequadamente a diferentes demandas trazidas pelas mulheres, mas que dependiam também de ações direcionadas para seus respectivos parceiros. Entre estas é possível citar o controle e a prevenção das doenças sexualmente transmissíveis (DSTs), a discussão sobre métodos contraceptivos e suas relações com o planejamento familiar, as diferentes situações de violência nas relações interpessoais, em especial, a violência praticada pelo parceiro.

Uma das primeiras atividades neste sentido fazia parte da ampliação do plano de ações para a prevenção das DSTs. Foi proposta a criação de um grupo educativo direcionado para homens e mulheres denominado Saúde e Sexualidade, cujo enfoque ia além da discussão da prevenção das DSTs e envolvia outras questões relacionadas à sexualidade como, por exemplo, o conhecimento sobre o corpo masculino e feminino, a importância da atividade sexual e a vivência do prazer para ambos os sexos, as concepções de gênero e sua importância no cotidiano dos relacionamentos (relações de confiança e fidelidade, por exemplo) e sua importância na prevenção das doenças.

Nessa época começaram a surgir idéias relacionadas à construção de um programa específico de atenção integral à saúde do homem. As discussões direcionavam-se para uma organização que contemplasse os referenciais das relações de gênero. As ações deveriam prever uma interação prática com os pressupostos do programa de atenção à saúde da mulher. Além disso, havia também a intenção de ampliar a visibilidade dos homens no serviço, em duas vias: por parte da instituição, estimulando a percepção dos profissionais em relação às necessidades dos homens; por parte da população masculina, promovendo um reconhecimento do espaço institucional como sendo de sua necessidade.

Foi iniciado então o processo de elaboração e planejamento de atividades direcionadas aos homens. As atividades deveriam ser desenvolvidas de diferentes formas (grupos de discussões, oficinas ou atividades assistenciais individuais) e em espaços diversos (no próprio CSE como também na própria comunidade) para ampliar as possibilidades de participação.

Atualmente, realizam-se discussões em sala de espera de atendimento sobre diferentes temas relacionados às masculinidades e saúde como, por exemplo, alcoolismo, violência e paternidade, sendo estas conversas uma forma de sensibilizar a população que tem acesso ao CSE sobre a questão da saúde dos homens. As discussões geram bastante polêmica, indicando o interesse da população pelo tema e a importância de sua inserção nas práticas assistenciais.

Entre as ações atuais, também ocorrem - e são cada vez mais estimuladas - atividades na comunidade. Nesse sentido, vale relatar uma experiência iniciada em 2003 durante um campeonato de futebol em um bairro da área de abrangência do CSE. Durante supervisão dos agentes comunitários de saúde (ACS), em atividade de discussão de relações de gênero, foi concebida a proposta de uma barraca junto das arquibancadas, com material educativo sobre os seguintes temas: sexualidade, a prevenção de DST/Aids e contracepção, violência no espaço público e a violência doméstica e alcoolismo. A estratégia para abordagem dos homens foi a simulação de reportagem televisiva, na qual os ACS interpretavam repórteres entrevistando os homens, perguntando, por exemplo: "Você acha que os homens cuidam adequadamente de sua saúde?" "Você usa camisinha em todas as suas relações?" Em seguida, os ACS estimulavam as pessoas a procurar a barraca para mais esclarecimentos. A barraca foi muito visitada tanto por homens quanto por mulheres, e o maior interesse foram os preservativos e informações sobre o acesso ao serviço de saúde. Atualmente o CSE mantém contato com os organizadores do campeonato de futebol, para a continuidade das atividades, propondo também a realização de oficinas e discussões de temas relacionados a futebol, masculinidade e saúde (violência, acidentes típicos do esporte, vida sexual e a prática de futebol, etc.). 
Uma nova atividade, em fase experimental, é a realização de um grupo educativo sobre homens e saúde no serviço. Seu objetivo é estimular a reflexão e a troca de experiências entre os homens e a equipe acerca de temas relacionados à saúde. Para a realização dessa atividade, foram afixados cartazes e distribuídas filipetas, tanto no CSE quanto na própria comunidade, convidando os homens a participarem. Vale ressaltar que a atividade está programada para um horário mais flexível (mais tarde), possibilitando, assim, uma maior participação dos homens.

O relato acima descrito não deve representar uma receita pronta para ser imediatamente utilizada por qualquer outra unidade de atenção primária à saúde. A própria experiência do CSE leva a pensar no quanto o desenvolvimento de ações de prevenção e promoção à saúde dos homens está vinculada às especificidades de cada local, às características da equipe multiprofissional responsável pelo serviço, como também às necessidades de saúde sentidas nas práticas assistenciais prestadas. Entretanto, mesmo sem generalizar, esta experiência pode estimular outras unidades básicas de saúde no desenvolvimento de ações que contribuam para práticas cotidianas mais saudáveis por parte da população masculina.

O desafio lançado para as UBS é estudar o desenvolvimento de trabalhos voltados para os homens em uma perspectiva de gênero. Somente desta forma será possível aumentar a visibilidade das necessidades específicas da população masculina, compreendida em um contexto sociocultural, a partir de ações mais efetivas para o cuidado de saúde.

\section{Referências bibliográficas}

Connell RW 1995. Masculinities: knowledge, power and social change. University of California Press. Berkeley, Los Angeles.

Courtenay WH 2000. Construction of masculinity and their influence on men's well-being: a theory of gender and health. Social Science \& Medicine 50:13851401.

Korin D 2001. Novas perspectivas de gênero em saúde. Adolescência Latino-Americana 2(2):67-79.

Laurenti R et al. 1998. Perfil epidemiológico da saúde masculina na região das Américas. Uma contribuição para o enfoque de gênero. Faculdade de Saúde Pública/USP, São Paulo.

Sabo D 2000. Men's health studies: origins and trends. Journal of American College Health 49:133-142.

Scott J 1995. Gênero: uma categoria útil para a análise histórica. SOS Corpo, Recife.

Schraiber LB \& Mendes-Gonçalves RB 2000. Necessidades de saúde e atenção primária, pp. 29-47. In LB Schraiber, MIB Nemes \& RB Mendes-Gonçalves (orgs.). Saúde do adulto: programas e ações na unidade básica. Hucitec, São Paulo. 